\section{DE DE GRUYTER}

OPEN

G

Joanna Jończyk ${ }^{34}$

Bialystok University of Technology

Beata Buchelt ${ }^{35}$

Cracow University of Economics
Journal of Intercultural Management

Vol. 7, No. 2, June 2015, pp. 135-150

DOI 10.1515/joim-2015-0015

\title{
Employee Appraisal as the Tool of the Pro-innovative Organizational Culture Formation in Hospitals ${ }^{36}$
}

\begin{abstract}
Healthcare sector is considered as the knowledge-based sector and because of this innovation and creativity should be regarded as prerequisite for the survival and growth of the organizations which perform their activities within the sector. In this context development of pro-innovative culture within hospitals becomes crucial. In search for tools allowing to create the culture employees appraisal becomes an interesting tool to be further investigated. Due to the fact the main aim of the paper is to investigate the relationships between the employee appraisal system and innovation in the context of the organizational culture in the hospitals. Study was carried in eight public hospitals located in two voivodships in Poland. Not only qualitative but also quantitative data was analyzed in order to identify usefulness of employees appraisal as the tool of proinnovative culture creation.

Key words: organizational culture, innovative culture, employees' appraisal, performance appraisal, health care entities, hospitals

\footnotetext{
34 j.jonczyk@pb.edu.pl

35 bucheltb@uek.krakow.pl

${ }^{36}$ The discussion presented in his article is the effect of the research project conducted by $\mathrm{dr}$ Joanna Jończyk - "Developing pro-innovation organizational culture in public hospitals" - financed from the funds allocated to the project NCN 2011/03/B/HS4/0454 and the research project conducted by dr Beata Buchelt - "Human capital management in hospitals" - financed from the funds allocated to the project NCN 2013/11/B/HS4/01062.
} 


\section{Introduction}

In the realities of the modern knowledge economy, innovation and creativity are considered to be the prerequisite for the survival and growth of an organization. As a consequence, human resources - as the source of new or creatively transformed solutions - need to be used effectively. This view is of decisive significance in the context of pro-innovative organizational culture, the development of which is one of the priorities due to the growing importance of innovation and the necessity to implement innovative solutions. In order to prepare employees to adopt proinnovative culture, however, managers need to make changes in the existing human resource management practices and policies [Denning 2011]. One of the tools used to implement such changes is the employee appraisal system. An efficient system may become an important instrument supporting the development of employees' competencies, which, in turn, allows for the development of proinnovative organizational culture. It should be noted, however, that literature does not provide the results of research on the relationships between employee appraisal and innovation and their impact on pro-innovative organizational culture. Thus, the issue gains in importance, in particular with reference to hospitals, which are recognized for the unique characteristics of their environment, structure or organizational processes [Fraczkiewicz-Wronka 2009]. The primary goal of this study is to investigate the relationships between the employee appraisal system and innovation in the context of the organizational culture in the hospitals participating in the study. First, we carried out the literature review, then we presented the research methodology and discussed the results of our empirical research conducted in 2014 in 8 hospitals operating in Poland. In the conclusion, we analyzed the implications and limitations of the study and indicated the need to expand scientific research into other HR practices and their role in building pro-innovative organizational culture.

\section{The formation of pro-innovative organizationl culture}

As a result of growing significance of innovation, it is not an overstatement to propose that the formation of pro-innovative organizational culture is one of the priorities of today's organizations. In order to achieve long-term success in the competitive world, the development of pro-innovative organizational culture seems simply a necessity [Chen, Huang 2009]. This poses a particularly difficult challenge for management, even more so that it requires changes not only in management procedures and mechanisms, but, first of all, in employees' attitudes and behaviors. Moreover, staff is identified as an obstacle to the formation of pro-innovative culture, while, on the other hand, its active involvement is indispensible in the very same process [Horibe 2001, p. 192]. This appears to justify the attempts to seek the links between employees' values, convictions and behavioral patterns and innovation in the context of building pro-innovative organizational culture. 
Literature indicates that one of the ways to link organizational culture with innovation is the personnel function [Tesluk, Faar, Klein 1997, pp. 21-41]. Applying HRM practices to the promotion of creativity, knowledge and innovation, it facilitates the formation of pro-innovative organizational culture [Tan, Mohd Nasurdin 2011, pp. 155-167]. It is important to stress here that creativity and innovation are closely related, but not identical [Angle 1989, pp. 135-170]. Creativity involves developing new and useful ideas, primarily at an individual level [Amabile, Conti, Coon, Lazenby, Herron 1996, pp. 1154-1185]. Innovation, on the other hand, is the process of successful implementation of creative ideas in an organization, mainly at a group level, but also at an organizational level. In the context of building pro-innovative organizational culture, which promotes creativity and innovation, the works of Amabile and her colleagues are particularly interesting. The authors identified a number of factors conducive to developing pro-innovative organizational culture, such as organizational encouragement, supervision, team work, freedom, sufficient resources, and challenges. Kanter, on the other hand, identifies such factors as integrative organizational structure, variety within an organization, collective pride and faith in people's talent, collaboration and teamwork [Kanter 1983]. The author also indicates the obstacles to building pro-innovative culture, involving excessive control, hierarchical structures and lack of supervisory support. She stresses that managers working within pro-innovative organizational culture have to win the support and power for their ideas through persistence and convincing argumentation [Kanter 1983, p. 179]. Ismail underlines the importance of communication and information sharing inside and outside an organization [Ismail 2005, pp. 639-654] and, in particular, the need for high-frequency communication among individuals from different systems (occupational groups, positions), as he points out that the exchange of ideas generated form different perspectives will lead to the emergence of new, creative ideas. Tesluk et al. identify five dimensions of organizational climate affecting creativity. They include the emphasis on goals relating to creativity and innovation, the emphasis on norms and procedures relating to creativity and innovation, reward orientation, task support, involving also emotional support [Tesluk, Faar, Klein 1997, pp. 21-41]. If an organization strongly communicates that creativity and innovation are its important goals, people are more likely to develop creative behaviors. The clarity of goals allows employees to concentrate on solving problem and generating ideas instead of attempting to define objectives. If managers act and communicate in a way showing that they appreciate and follow procedures relating to risk taking, information sharing and open debate, employees are more willing to take up such behaviors. Recognition of and reward for creativity and innovative performance afford employees internal motivation. Moreover, while building pro-innovative culture, it is equally important to support staff by providing them with time, resources, equipment and materials necessary to implement new 
ideas, projects and solutions. Finally, emotional support should be given, as it builds the work environment conducive to free creative activity. When employees can see that their organization works for its good as well as theirs, when the environment for open debate and discussion is in place, their trust increases and, as a consequence, encourages them to take risks and come up with creative ideas.

Martins and Martins further developed the concepts relating to the conditions conducive to the formation of pro-innovative culture. While studying the relationships between organizational culture and innovation, the authors indicated the necessity to combine activities comprising eight areas. The areas include an organization's strategy, a organizational structure, goal orientation, trust relationships, innovation stimulating behaviors, an internal environment, (internal and external) customer orientation, managerial support [Martins, Martins 2002, pp. 58-65; Martins, Terblanche 2003, pp. 64-74].

Summing up, it should be emphasized that all of the above factors relating to the formation of pro-innovative organizational culture should be given more support from HRM practices. Their adequate design and implementation definitely motivate employees to develop competencies connected with creativity and innovation, necessary to create added value in new or creatively transformed solutions. The article recognizes the employee appraisal system as a major human resource management tool in building pro-innovative organizational culture.

\section{Employee appraisal as a tool of building pro-innovative culture}

Employee appraisal is one of the most frequently explored areas of human resources management. This applies both to Polish and English language literature. Publications on employee appraisal analyze a diversity of aspects, for example, the architecture of employee appraisal systems, the objectives of employee appraisal, the activity of entities involved in employee appraisal, assessment criteria, supporting tools, and challenges posed by the implementation and management of employee appraisal [cf. Jackson, Schuler 2003; Czubasiewicz 2005; Sidor-Rządkowska 2006; Abu-doleh, Weir 2007; Myrna 2009; Sillup, Klimberg 2010]. The rationale behind the researchers' attempts to analyze employee appraisal in an organization is the fact that its prime goal is to increase a company's effectiveness through the optimum use of employees' potential [Funkcja personalna (...), 2007, Pocztowski. 2007].

Literature defines employee appraisal as the process oriented towards the identification of employee potential [Bratton, Gold 2003]. Other definitions emphasize that the goal of the employee appraisal process is the thorough analysis of employees' performance, needs and development potential, necessary to plan and implement human resources management measures aligned with an enterprise's strategy and mission [Juchnowicz, Rostkowski, Sienkiewicz 2005]. Appraisal may only perform its role when it is not conducted sporadically or incidentally, but 
when it is rooted in the assessment system, including the following components: assessment goals, rules, criteria, subjects, objects, techniques, procedures, and frequency of appraisal [Sidor-Rządkowska 2006; Pocztowski 2007].

The literature review has revealed that the contemporary approach to employee appraisal departs from one-off measures aiming to assess employee performance, which are held on an annual basis as periodic appraisals, to adopt a more holistic perspective, which is referred to as performance management in literature. This approach is based on the global view of an employee's work, as it assesses both an employee's performance and their competencies and behaviors in relation to the position that they hold [Armstrong 2002; Williams 2002]. The perception of employee appraisal as a process instead of a one-off act focused on the effects of an employee's work allows an organization to shape its human capital and employee behaviors involved in task performance in such a manner that they create, or even exceed, the effects pursued by an organization. This link forms the foundation for the analysis and discussion presented in the article, as it is assumed that assessment criteria determine the development of the adequate employee competencies on one hand and stimulate their pro-effective behaviors on the other hand. As a result, employees succeed in achieving the defined effects of work. Aggregate individual effects of work contribute to the achievement of both group and organizational effects.

\section{Research assumptions and methodology}

Based on the literature review, the article makes the following assumptions: 1) organizations aspiring to form pro-innovative organizational culture with the use of employee appraisal should develop the appraisal system comprising the criteria that will stimulate employee's creativity and innovativeness, and 2) such a system, when it is effective, will lead to innovativeness in hospitals (see Chart 1).

Chart 1. The relationship between the employee appraisal system and hospital innovativeness

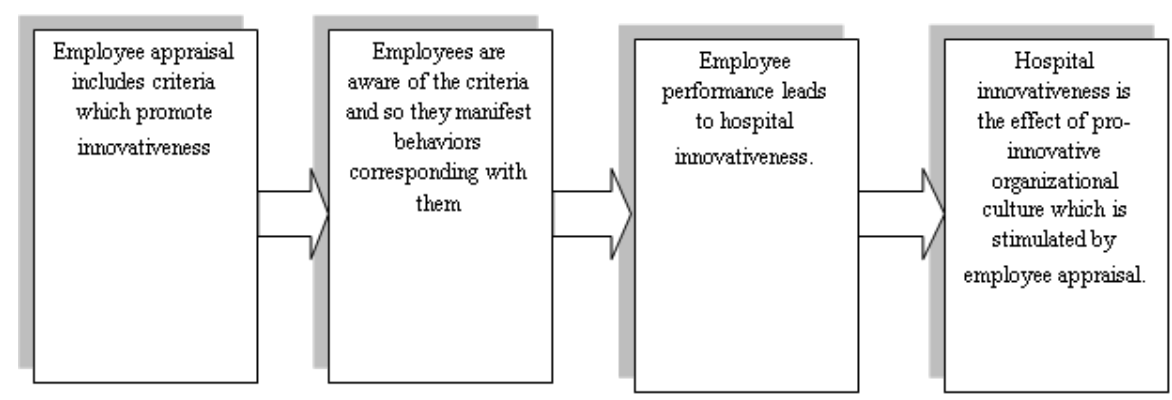

Source: own elaboration. 
The adoption of these assumptions allowed for the elaboration of the following research problems:

- Do the researched hospitals have periodic employee appraisal systems?

- Do the assessment criteria used in the hospitals include the criteria conducive to innovation?

- Does employee appraisal affect hospital innovativeness?

In order to address the research problems, we used the data acquired through qualitative and quantitative research conducted in eight public hospitals, operating in two voivodeships in Poland, in 2014. It should be noted that the choice of the hospitals was deliberate and stemmed from the fact that they were the only organizations that agreed to take part in the study. Qualitative data came from the internal documentation of the hospitals and non-standardized interviews with the hospital management. Quantitative data, on the other hand, was collected in the survey carried out among 556 respondents, including doctors, nurses, midwives, managers, and representatives of the remaining occupational groups. We analyzed all the questionnaires (556), the majority of which were completed by nurses and midwives (285 questionnaires). The remaining questionnaires came from doctors (100 questionnaires), management (comprising hospital directors, deputy directors, managers, hospital ward heads, head nurses -82 questionnaires), and other staff (89 questionnaires). In the context of the research assumptions and problems, the quantitative exploration comprised two questions from the questionnaire. The first question was whether the hospital's employee appraisal system comprised the criteria related to creativity and innovation (Does the hospital use the employee appraisal system that comprises the criteria related to creativity and innovation?). Respondents answered the question on a 5-item scale with the following options: "definitely yes", "rather yes", "no opinion", "rather no", "definitely no". The second question concerned hospital innovativeness ("Is the hospital innovative?"). In order to make the scale more sensitive, we offered seven options in the Likert scale: 1 - "definitely no", 2 "no", 3 - "rather no", 4 - "no opinion", 5 - "rather yes", 6 - "yes", 7 - "definitely yes". In the light of the goal of the publication, we defined the key element of empirical verification as an attempt to investigate the relationship between hospital innovativeness and employee appraisal comprising the criteria related to creativity and innovation. Due to the ordinal type of variables and the awareness of violation of classic ANOVA assumptions (lack of normality in sub-groups resulting from the ordinal type of data, heterogeneity of variances), the analysis uses the ANOVA Kruskal-Wallis test by ranks.

\section{Empirical research results}

The results of the qualitative study clearly confirm that the hospitals use employee appraisal. All the entities have the employee appraisal system, usually 
adopted as a separate regulation. The document stipulates the rules of employee appraisal, stemming from the evaluation of the entirety of tasks performed in a given position, defined in a job description. Employee appraisal in the researched hospitals aims to support the optimum personnel policies, including employee professional development and staff motivation. Employee appraisal also allows for the complex verification of tasks performed by employees in their positions in terms of the goals defined for them and their vocational fitness to a given position. The hospitals conduct employee appraisal on an annual basis with an exclusion of employees working less than 6 months. It is performed by an immediate superior, who assesses employees working directly under his supervision. Two of the hospital also conduct self-appraisal, which comprises all employees subject to the appraisal procedure. Employee appraisal is carried out with the use of an appraisal form. Six hospitals apply a numerical scale, two - a descriptive scale. The analysis of the appraisal forms reveals that the assessment criteria include the criteria stimulating creativity and pro-innovative employee behaviors, for example knowledge, professional development, teamwork, communication, independence, initiative and commitment.

In the context of the research assumptions underlying the publication, the results of the quantitative survey were also of great significance. First, we determined the level of employee awareness of the employee appraisal system and its pro-innovative nature. For this purpose, we analyzed the answers to the following question: Does the hospital use the employee appraisal system that comprises the criteria related to creativity and innovation? (see Chart 2).

Chart 2. Awareness of pro-innovative criteria among hospital employees

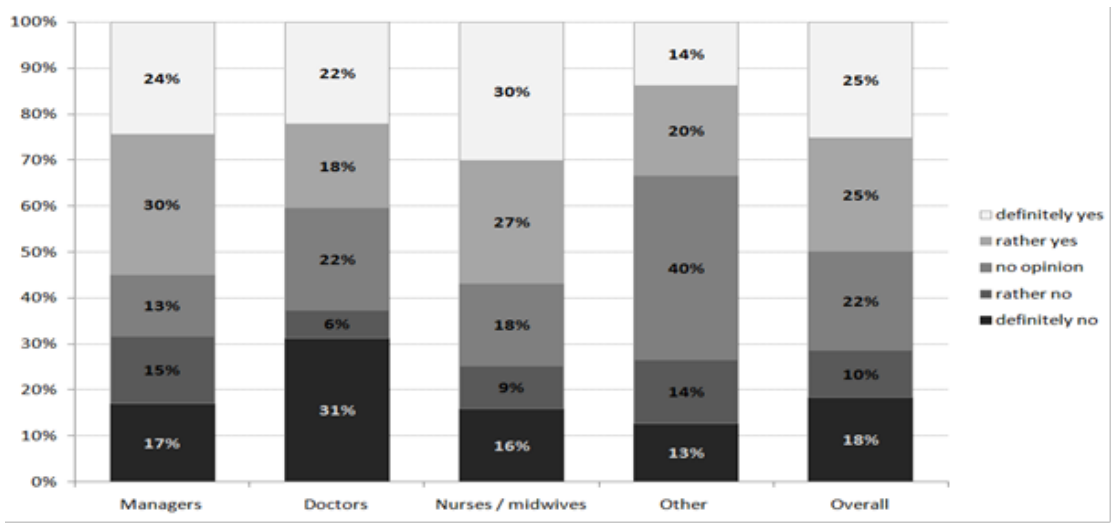

Source: Own elaboration based on empirical research.

The respondents confirmed that on average $50 \%$ of staff recognized the criteria stimulating creativity and innovation. The highest rate of recognition was obtained 
in the groups of nurses/midwives and managers. The poorest awareness was observed among doctors and other hospital staff.

In the context of the formulated research assumptions, it was also crucial to check whether the researched hospitals were innovative. For this purpose, the following question was asked: Is the hospital innovative? (Chart 3). The distribution of responses indicates that more than $50 \%$ of the respondents acknowledge the innovativeness of the hospital. The highest percentage of such responses was obtained in the groups of managers and nurses/midwives, whereas the lowest among doctors and other hospital staff, similarly as in the case of the opinions on employee appraisal.

Chart 3. Hospital innovativeness in the opinion of hospital employees

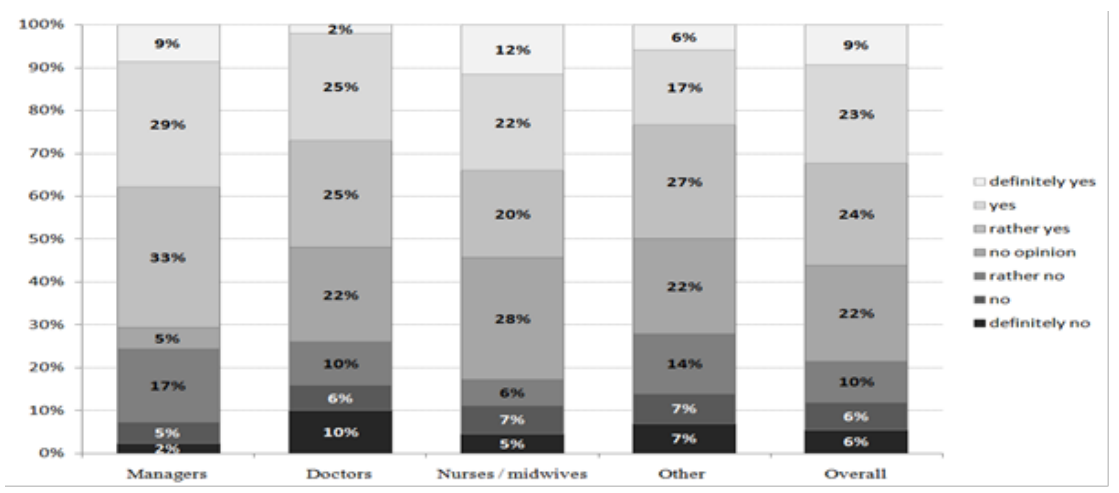

Source: own elaboration based on empirical research.

While analyzing the results, we found it interesting to explore whether an occupational group determined the opinion on hospital innovativeness. To investigate the issue, we applied the analysis of variance (the ANOVA KruskalWallis test by ranks), which yielded the statistic $\mathrm{H}=8.509$ (at free degrees of freedom) and the level of significance at 0.037 . With the level of significance at 0.05 , it was determined that the respondents' opinions on hospital innovativeness varied significantly for particular occupational groups. Therefore, in addition to exploring the differences within the entire sample, further considerations also account for the responses within particular occupational groups.

Then, using the same Kruskal-Wallis test, we compared hospital innovativeness with employee appraisal, where the grouping variable was the fact whether such appraisal was conducted in a given hospital. The verification results (Table 1) show how the assessment of innovativeness compares against employee appraisal practices, including the criteria related to employee creativity and innovation, both for the entire sample and for particular groups. 
Table 1. Results of the analysis of variance for the comparison of the assessment of innovativeness and the employee appraisal system, in total and by occupational groups

\begin{tabular}{|l|l|l|l|}
\hline Position & $\begin{array}{l}\text { Degrees of } \\
\text { freedom }\end{array}$ & H statistics & p level \\
\hline Total & 4 & 72.816 & 0.000 \\
\hline Managers & 4 & 30.262 & 0.000 \\
\hline Doctors & 4 & 28.084 & 0.000 \\
\hline Nurses/midwives & 4 & 26.988 & 0.000 \\
\hline Overall & 4 & 6.444 & 0.168 \\
\hline
\end{tabular}

Source: own elaboration based on empirical research.

According to the obtained data, the respondents who confirmed their hospital had the employee appraisal system including the criteria related to creativity and innovation had a different view on hospital innovativeness. When the researched sample is broken down by occupational groups, it can be observed that these differences are significant both for doctors and for nurses/midwives or managers (in the ANOVA test that we conducted, the level of significance is much below the limit value, i.e. 0.000). Similar differences in the perception of hospital innovativeness cannot be observed in other groups of hospital employees (in the ANOVA test that we conducted, the level of significance is much above the limit value, i.e. 0.168). The reason may for this be the fact that this group of employees is not homogenous in terms of their opinions in this respect, as it is made up of different employees, both medical workers (e.g. medical analysts, operating theatre nurses, pharmacists) and administrative staff (e.g. accountants, maintenance workers).

In order to explore detailed opinions on the relationship between innovativeness and the employee appraisal system including the criteria related to creativity and innovation, the distributions of data for particular occupational groups, based on the arithmetic means for the assessments of innovativeness, are presented below. Chart 4 shows the managers' average responses about the assessments of innovativeness in comparison with the employee appraisal practices including the criteria related to creativity and innovation. 
Chart 4. The average values of the opinions on the level of innovativeness for managers opting for different responses regarding the employee appraisal system including the criteria related to creativity and innovation, as compared to the results of the total sample

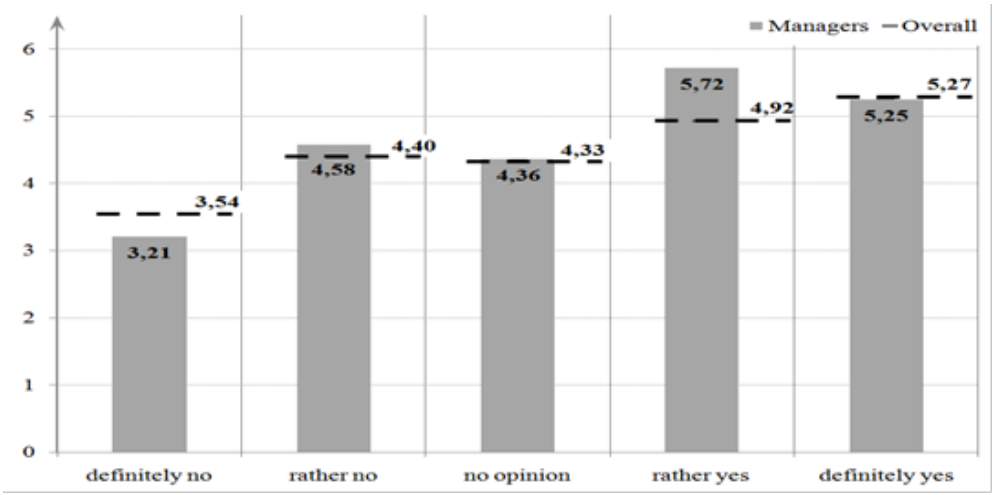

Source: own elaboration based on empirical research.

As the distribution of data indicates, the managers who confirmed that their hospital used the employee appraisal system including the criteria related to creativity and innovation (responses "definitely yes" and "rather yes") highly rated hospital innovativeness (the average values of responses at 5.72 and 5.25). On the other hand, those who did not confirm that their hospital used the employee appraisal system (responses "definitely no" and "rather no") or did not express any opinion on this issue rated innovativeness low (the average values of responses at 3.21 and 4.58). Accordingly, a higher opinion about the employee appraisal system is accompanied by a higher rating of the innovativeness of a hospital, which confirms the correlation between the two variables.

Another group the opinions of which were analyzed were doctors. Their average responses are presented in Chart 5. The analysis of the data on the doctors' opinions leads to similar conclusions as in the case of the managers' opinions. The doctors who confirmed that their hospital used the employee appraisal system including the criteria related to creativity and innovation (responses "definitely yes" and "rather yes") equally highly rated hospital innovativeness (the average values of responses at 4.94 and 5.36). On the other hand, those who did not confirm that their hospital used the employee appraisal system (responses "definitely no" and "rather no") or did not express any opinion on this issue rated hospital innovativeness equally low (the average values of responses at 3.13 and 3.83). The doctors' negative opinions, however, are lower that the managers' opinions, which may indicate the stronger awareness of the former with respect to the necessity of linking employee appraisal with hospital innovativeness. 
Chart 5. The average values of the opinions on the level of innovativeness for doctors opting for different responses regarding the employee appraisal system including the criteria related to creativity and innovation, as compared to the results of the total sample

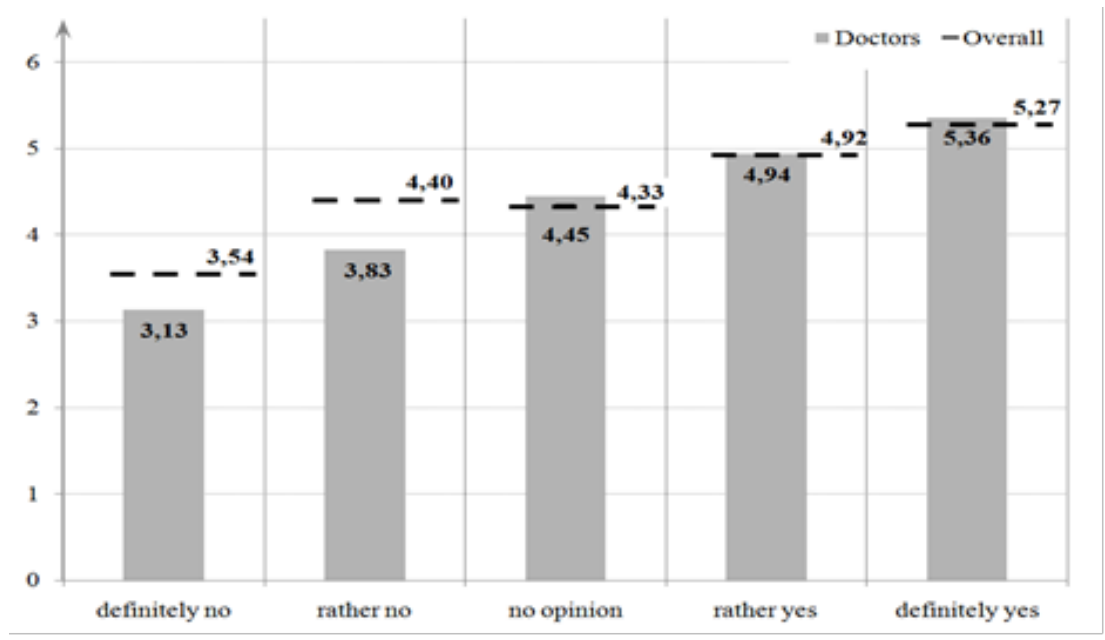

Source: own elaboration based on empirical research.

Another group of the respondents were nurses and midwives. Their average responses are presented in Chart 6 . The distribution of the data concerning the nurses' opinions are similar to the ones coming from the managers and the doctors. The nurses and midwives who confirmed that their hospital used the employee appraisal system including the criteria related to creativity and innovation (responses "definitely yes" and "rather yes") highly rated hospital innovativeness (the average values of responses at 4.73 and 5.29). On the other hand, those who did not confirm that their hospital used the employee appraisal system (responses "definitely no" and "rather no") or did not express any opinion on this issue rated the innovativeness of the hospital low (the average values of responses at 3.64 and 4.64). It should be noted that the values for their negative opinions are higher than in the case of the opinions of the doctors and managers, which, in turn, may lead to the conclusion about their weaker awareness of the relationship between the employee appraisal system and hospital innovativeness. 
Chart 6. The average values of the opinions on the level of innovativeness for nurses opting for different responses regarding the employee appraisal system including the criteria related to creativity and innovation, as compared to the results of the total sample

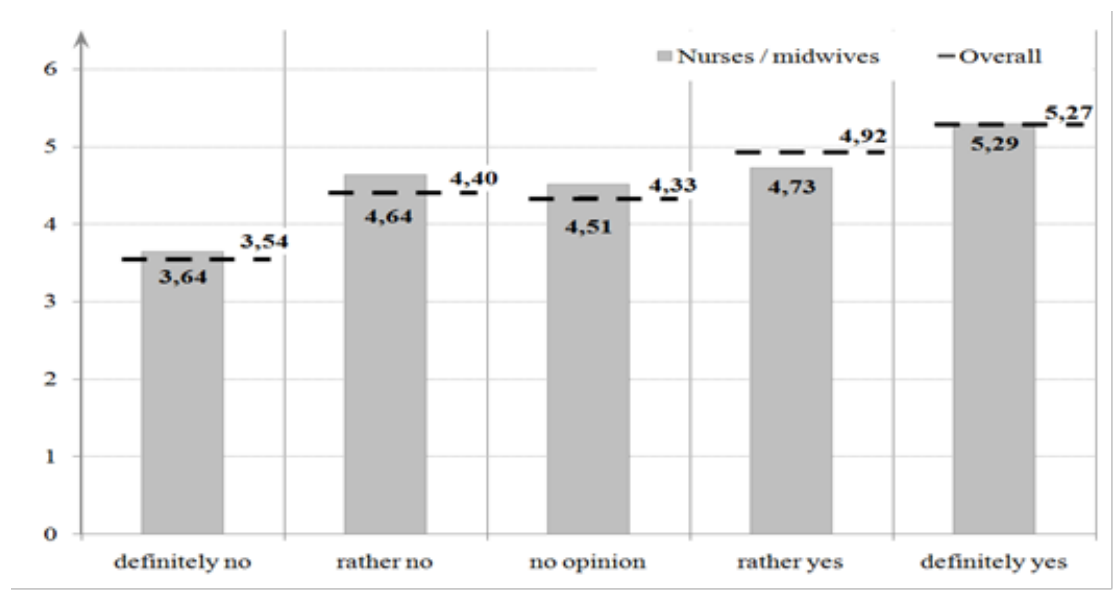

Source: own elaboration based on empirical research.

The last group of respondents was the group of other hospital staff (Chart 7). The analysis of the presented data indicates that the opinions within this group on the link between the employee appraisal system and hospital innovativeness are the most varied. This is probably caused by the greatest diversity of this group, which comprises both medical workers (e.g. medical analysts, operating theatre nurses, pharmacists) and administrative staff (e.g. accountants, maintenance workers). However, the average values of the negative opinions are higher than in the other occupational groups, while the average values of the positive opinions are lower. This may indicate that the awareness of these employees concerning the relationship between the employee appraisal system including the criteria related with creativity and innovation is the lowest. 
Chart 7. The average values of the opinions on the level of innovativeness for other hospital staff opting for different responses regarding the employee appraisal system including the criteria related to creativity and innovation, as compared to the results of the total sample

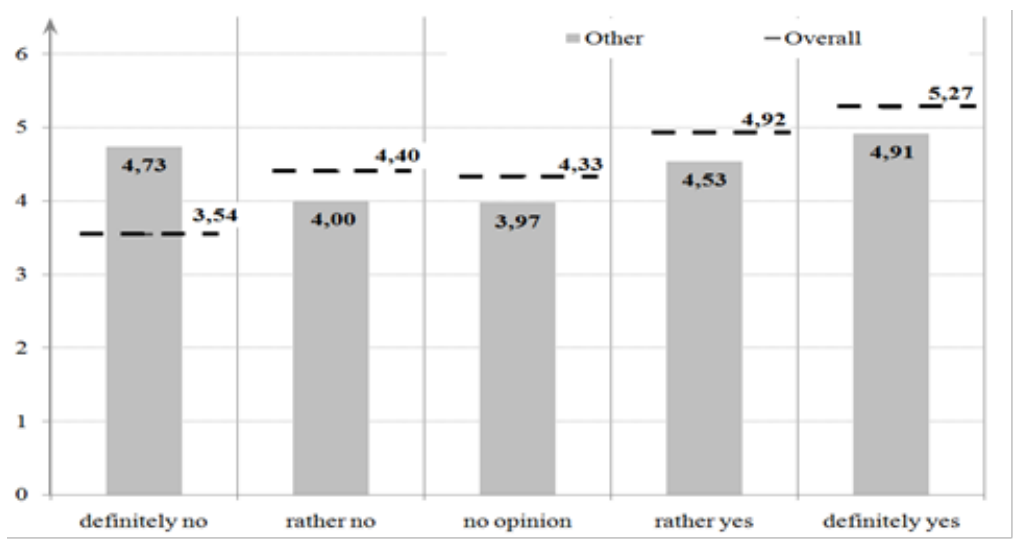

Source: own elaboration based on empirical research.

\section{Closing remarks}

Pro-innovative organizational culture is quickly becoming a priority in the pursuit of organizational success. It looks for new ideas, concepts, and knowledge in order to create innovation giving competitive advantage over other organizations. Yet, pro-innovative organizational culture requires the departure from the old HRM practices and policies ensuring organizational stability to the new practices that motivate employees to seek innovative knowledge needed at the times of constant change characterizing the modern organization. The employee appraisal system including the criteria related with creativity and innovation plays an important role in such an environment. Such a system may become a crucial tool motivating employees to change and adopt pro-innovative behaviors. As behaviors are the manifestations of their way of thinking and hierarchy of values, the periodic appraisal system may contribute to the formation of pro-innovative organizational culture.

Considering the strategic importance of employee appraisal for the formation of pro-innovative organizational culture, the article attempts to determine the impact of the employee appraisal system on building pro-innovative organizational culture in hospitals. The adopted assumption was verified based on the analysis of both qualitative and quantitative data. It was established that the researched hospitals 
used periodic employee appraisal systems that included the criteria stimulating proinnovative behaviors among employees and that employees were aware that the hospital had such a system in place.

The main problem was to determine whether the relationship existed between the awareness of the criteria stimulating innovation with the actual innovativeness of hospitals. Accordingly, the research results show that the highest average values of the opinions on the links between the employee appraisal system and hospital innovativeness came from the managers and doctors, respectively lower - the nurses and midwives, while the lowest were expressed by other hospital staff. In the case of negative responses, the lowest responses were expressed by the doctors and managers, higher averages came from the nurses and midwives and the highest from other hospital staff. As a consequence, it can be stated that the occupational groups crucial from the perspective of hospitals (managers, doctors, nurses and midwives) are aware that employee appraisal is a tool that can be used to increase hospital innovativeness. Certain limitations affecting the study, however, should be defined. First of all, there are significant differences in terms of the sizes of the respondent groups, which could have affected the results (yet, it was not possible to collect more questionnaires from less numerous groups that doctors and managers are in every hospital). Moreover, the group comprising other hospital staff was strongly diversified, as it comprised both the representatives of medical professions and administrative staff. Finally, the study was conducted only in selected hospitals in two voivodeships. As a result, it cannot be seen as a significant research achievement, but it offers an opening for further empirical research in the area. There is a limited number of studies into the role of employee appraisal in the formation of pro-innovative organizational culture, especially in the subcultural context of healthcare organizations. Moreover, the study may be an important indication for hospital directors and HR specialists on how to improve their employee appraisal systems so that they can include the criteria related to creativity and innovation, so important for the formation of pro-innovative organizational culture.

\section{References}

Abu-doleh J., Weir D. (2007), Dimensions of Performance Appraisal Systems in Jordanian Private and Public Organizations, "International Journal of Human Resource Management", No. 18(1), pp. 75-84.

Amabile T.M., Conti R., Coon H., Lazenby J., Herron M. (1996), Assessing the work environment for creativity, "Academy of Management Journal", 39(5), pp. 1154-1185.

Angle H.L. (1989), Psychology and organizational innovation [in:] A.H. Van de Ven, H.L. Angle, M.S. Poole (Eds.), Research on the management of innovation: The Minnesota studies (pp. 135-170). New York: Harper \& Row.

Armstrong M. (2002), Performance Management. Key Strategies and Practical Guidelines, Kogan Page Limited, London-Dover. 
Bratton J., Gold J. (2003), Human Resource Management: Theory and Practice, Palgrave Macmillan. Burns, T., Stalker G.M. (1961), The Management of Innovation, Tavistock Publishing, London.

Chen C.J., Huang J.W. (2009), Strategic human resource practices and innovativeness performance. The mediating role of knowledge management capacity, "Journal of Business Research", Vol. 62, No.1, pp. 104-114.

Czubasiewicz H. (2005), Okresowe ocenianie pracowników. Konfiguracja i projektowanie systemu, Wydawnictwo Uniwersytetu Gdańskiego, Gdańsk.

Frączkiewicz-Wronka A. (2009), Zarzqdzanie publiczne w teorii i praktyce ochrony zdrowia, Wolters Kluwer, Warszawa, pp. 129-130.

Horibe F. (2001), Creating the innovation culture: leveraging visionaries, dissenters and other useful troublemakers in your organization, John Wiley \& Sons.

Ismail M. (2005), Creative climate and learning organization factors: their contribution towards innovation, "Leadership and Organization Development Journal", Vol. 26, no. 8, pp. 639-654.

Jackson S.E., Schuler R.S. (2003), Managing Human Resources Through Strategic Partnership, Thomson South-Western.

Jaskyte K., Kisieliene A. (2006), Organizational innovation a comparison of nonprofit buman-service organizations in Lithuania and the United States, "International Social Work", Vol. 49 No. 2, pp. 165-176.

Juchnowicz M., Rostkowski T., Sienkiewicz L. (2005). Narz̨edzia i praktyka zarzqdzania zasobami ludzkimi, Poltext, Warszawa.

Kanter R.M. (1983), The change masters: Innovation for productivity in the American corporation, New York: Simon \& Schuster.

Kimberly J.R., Evanisko M.J. (1981), Organizational innovation: the influence of individual, organizational, and contextual factors on hospital adoption of technological and administrative innovations, "Academy of Management Journal" Vol. 24, pp. 689-713.

Martins E., Martins N. (2002), An organizational culture model to promote creativity and innovation, "Journal of Industrial Psychology", 28 (4), pp. 58-65.

Martins E., Terblanche F. (2003), Building organizational culture that stimulates creativity and Innovation, "European Journal of Innovation Management", Vol. 6 No. 1, pp. 64-74.

Myrna J.W. (2009), Turning the tables on performance reviews: how to create a better process that empowers and rewards your employees, "Business Strategy Series”, No. 10(6), pp. 366-373.

Pocztowski A. (2007), Zarzadzanie zasobami ludzkimi. Strategie - procesy - metody, PWN, Warszawa.

Funkecja personalna. Diagnoza i kierunki zmian (2007), Pocztowski A. (ed.), Wydawnictwo UEK, Kraków.

Sidor-Rządkowska M. (2006), Kompetencyjne systemu ocen pracowników. Przygotowanie, wdrażanie $i$ integrowanie z innymi systemami ZZL, Wolters Kluwer Polska Oficyna Ekonomiczna, Kraków. 
Sillup G.P., Klimberg R. (2010), Assessing the ethics of implementing performance appraisal systems, "Journal of Management Development", No 29(1), pp. 38-55.

Tan C.L., Mohd Nasurdin A. (2011), Human Resource Management Practices and Organization Innovation, "Electronic Journal of Knowledge Management”, 9(2), pp. 155-167.

Tesluk P.E., Faar J.J., Klein S.R. (1997), “n”, “Journal of Creative Behaviour”, Vol.31 No. 1, pp. 21-41.

Williams R. (2002), Managing Employee Performance: Design and implementation in organizations, London: Thomson Learning.

\section{Internet sources - www}

Denning S. (2011), How do you change an organizational culture?, Available: http://www.forbes. com/sites/stevedenning/2011/07/23/how-do-you-change-an-organizational-culture/ [15.09.2015]. 